\title{
Male Circumcision; Willingness to undergo Safe Male Circumcision and HIV Risk Behaviors among Men in Botswana
}

\author{
Mpho Keetile ${ }^{1 a}$ \& Serai Daniel Rakgoasi ${ }^{b}$ \\ a Department of Population Studies, ${ }^{b}$ Department of Population Studies \\ University of Botswana, Private Bag 00705, Gaborone, Botswana
}

\begin{abstract}
This paper uses data from the 2008 Botswana AIDS Impact Survey to explore the association between male circumcision or willingness to undergo safe male circumcision, and men's sexual and HIV risk behaviours in Botswana. Bivariate and multivariate regression analysis techniques are used. The results show that being circumcised, or expressing willingness to be circumcised, was associated with significant increase in the likelihood of having two or more current sexual partners, and having had sex with multiple partners during the year leading to the survey, even after controlling for confounding variables.

There is a need for further research to examine the association between male circumcision and men's sexual practices in Botswana. Such context specific research will provide the necessary evidence base for HIV prevention and impact mitigation programs, interventions and strategies and to provide rigorous estimates of the extent men's sexual risk compensation and 'sexual disinhibition' associated with the reduced risk of HIV infection accorded by safe male circumcision. Current efforts to promote male circumcision as an integral part of the country's HIV prevention and control strategy need to be accompanied by continuous education to address myths and misconceptions relating to safe male circumcision.
\end{abstract}

Keywords: Botswana; Male, Safe Male Circumcision, Health; HIV/AIDS, Men

\section{Résumé}

Cet article utilise les données de l'enquête sur l'Impact de sida Botswana 2008 pour étudier l'association entre la circoncision masculine ou de volonté de subir une circoncision masculine sans danger et des hommes sexuelles et de comportements à risque du VIH au Botswana. Techniques d'analyse de régression bivariées et multivariées sont utilisés. Les résultats montrent que l'être circoncis, ou exprimant la volonté d'être circoncis, était associée à une augmentation significative de la probabilité d'avoir deux ou plusieurs partenaires sexuels actuels et ayant eu des relations sexuelles avec des partenaires multiples au cours de l'année, avant l'enquête, même après avoir tenu compte des variables confusionnelles.

Il est nécessaire de poursuivre les recherches examiner le lien entre la circoncision masculine et de pratiques sexuelles masculines au Botswana. Ces recherches spécifiques de contexte fournira la base de données nécessaire pour la prévention et l'impact des programmes d'atténuation du VIH, des interventions et des stratégies et de fournir des estimations rigoureuses de masculin mesure compensation sexuels à risque et "désinhibition sexuelle' associé à la réduction du risque d'infection à VIH attribuée par la circoncision masculine sans danger. Efforts actuels pour promouvoir la circoncision masculine comme partie intégrante de la stratégie de prévention et de contrôle du VIH du pays ont besoin d'être accompagné par la formation continue aux mythes de l'adresse et les idées fausses relatives à la circoncision masculine sans danger.

Mots-clés : Botswana ; Circoncision masculine, sans danger, santé ; Le VIH/sida, les hommes

\footnotetext{
${ }^{1}$ For correspondence: mphokeet@yahoo.com ; Phone (+267) 3552711
} 


\section{Introduction}

This paper investigates uncircumcised men's willingness to undergo safe male circumcision; and the association between men's willingness to undergo safe male circumcision and men's sexual and HIV risk behaviors in Botswana. The history of Botswana's HIV/AIDS epidemic is well documented (Kebaabetswe 2003, Ministry of Health 20II, Ayiga \& Letamo 20II). In 2008, national HIV/AIDS prevalence was estimated at $17.6 \%$ (compared to $17.1 \%$ in 2004) and HIV incidence rates were much higher among females (14\%) than males (2.9\%) (CSO 2009).

Evidence from research suggests that male circumcision reduces men's chances of HIV infection (Mattson et al 2005:I). Epidemiological evidence from studies in sub-Saharan Africa suggests that promotion of male circumcision has the potential to reduce the risk of HIV acquisition in men (Bailey et al. 1999; Kebaabetswe et al. 2003; Scott et al. 2005), and thus is a potential strategy for HIV prevention (Caldwell and Caldwell 1994; Nnko et al. 200I, Kebaabetswe et al. 2007). In fact, some ecological studies have shown that HIV infection rates are highest in traditionally non-circumcising societies of subSaharan Africa (Bongaarts et al. 1989; Caldwell and Caldwell 1994), thus making the practice of male circumcision more of a health issue (Caldwell and Caldwell, 1994; Halperin and Epstein, 1997; Nnko et al, 200I) than a cultural or religious one (Ntozi 1997). Over 40 sociological and epidemiological studies have shown a strong link between circumcision and reduced HIV prevalence in sub-Saharan Africa (Lagarde et al. 2003; Kebababetswe et al. 2003 and Rain-Taljaard et al 2003).

Three randomized clinical trials have also shown that men who are circumcised are less than half as likely to become infected with HIV within the trial periods (Bailey et al, 2002; Lagarde et al. 2003; Gray,. et al. 2003). In 2005, a randomized controlled trial conducted among uncircumcised men aged 1824 years in South Africa showed that male circumcision reduced the risk of acquiring HIV infection by $60 \%$ (Auvert et al 2005). Two further studies conducted in Uganda (Gray et al. 2003) and Kenya (Bailey et al. 2002) showed similar results. Based on the data from the clinical trials, models have estimated that routine male circumcision across sub-Saharan Africa could prevent up to six million new HIV infections and three million deaths in the next two decades (Weiss et al. 2000; Scott et al. 2003; Mattson et al 2005:I; Westercamp and Bailey 2006; Agot et al 2007; Bailey,. et al. 2007).

The accumulation of scientific evidence on the efficacy of safe male circumcision in reducing risk of HIV infection among heterosexual men has resulted in increased demand for male circumcision services in many African countries (Gray et al. 2000; Gray et al. 2003; Auvert et al 2005; Bailey et al. 2002). It is on the basis of such evidence that the government of Botswana incorporated safe male circumcision in the national HIV prevention program (2009), and followed this with the adoption of a strategy to promote pediatric circumcision of male infants as a way of reducing their risk of infection later in life (20I0).

However, the success of safe male circumcision, including pediatric circumcision, as a strategy to reduce the risk of infection depends on the level of acceptability it enjoys among the population. Safe male circumcision is widely accepted because of reasons relating to improved hygiene (Nnko et al 200 I; Mattson et al 2005); reduced incidence of STIs (Kebaabetswe et al. 2003) and reduced risk of HIV acquisition (Halperin et al. 2005; Scott et al. 2005). Studies on acceptability of male circumcision conducted in Kenya, Malawi, Zimbabwe, Swaziland, South Africa and Botswana show high levels of acceptability of safe male circumcision (Nnko et al. 2001; Bailey 2002; Largarde et al. 2003; Kebaabetswe et al.2003), even in traditionally noncircumcising communities (Mattson et al. 2005:2; Ngalande et al. 2005; Halperin et al. 2005; and Scott et al. 2005).

While safe male circumcision has the potential to reduce men's risk of HIV infection, some studies have suggested that the benefits of safe male circumcision are not guaranteed in contexts where there is widespread practice and acceptance of multiple concurrent sexual partnerships, especially by men (Serwadda et al. 1992; Gray et al 2003). In such contexts, the reduction in risk of HIV infection resulting from safe male circumcision could lead to increased sexual risk behavior (see Casell et al. 2006) and inconsistent condom use (see Ayiga \& Letamo 20II). Thus, safe male circumcision could promote "sexual dis-inhibition" if men interpret the reduction in risk of infection as a cue to continue or even intensify multiple concurrent sexual partnerships and even reduce the level of use of condoms during sex. So far, very little is known and understood about the association between men's willingness to undergo safe male circumcision and their sexual and HIV risk behaviors. 


\section{Theoretical Framework}

This paper is generally guided by the Health Belief Model (HBM) and adopts a multifaceted approach that considers HIV/AIDS risk perception among circumcised men and those who are willing to be circumcised by assessing their sexual risk behaviors. The Health Belief Model is a dominant individual psychological model, which attempts to explain and predict health behaviors and actions by focusing mainly on the attitudes, beliefs and perceptions of individuals (Rosenstock et al.1994). HBM has been used over the years to explore various health actions and behaviors, including sexual risk behaviors. The basic argument of HBM is the assumption that an individual's characteristics, perceptions, environment and previous experiences are key factors which shape their actions and perceptions of the risks and severity of the outcomes of their behavior (Auerbact et al. 1994).

Individual and social behavioral theories have often been used to explain why individuals are willing to undertake a certain action and why they behave the way they do. Individual behavior models focus on the role of individual characteristics in controlling individual behavior, thus they focus on how individuals control their behaviors and make reasoned actions that impact those decisions (Mberu 2010, Smith 2003), while the social models include social pressures, peer influences, cultural expectations, economic factors affecting resource availability, legal and political structures and political and religious ideologies that restrict individual's options and the flow of information (Smith 2003).

\section{Data \& Methods}

This study uses data derived from the 2008 Botswana AIDS Impact Survey III (BAIS III). BAIS III is the third and latest of a series of nationally representative demographic surveys aimed at providing up to date information on Botswana's HIV /AIDS epidemic. The 200I Botswana Population Housing Census provided the sample frame for BAIS III. This frame comprised the list of all Enumeration Areas (EA) together with the number of households. A stratified two-stage probability sample design was used for the selection of the sample. The first stage was the selection of EAs as Primary Sampling Units (PSUs) selected with probability proportional to measures of size (PPS), where measures of size (MOS) were the number of households in the EAs as defined by the 200I Population and Housing Census.

All 460 EAs were selected with probability proportional to size. At the second stage of sampling, the households were systematically selected from a fresh list of occupied households prepared at the beginning of the surveys' fieldwork. Overall, 8380 households were drawn systematically. A total number of 8,380 occupied households were sampled and 7,600 were successfully interviewed, yielding a household response rate of 91 percent. Within the 7600 completed households 16992 eligible respondents aged 10-64 years were identified and out of whom 15,878 were successfully interviewed, yielding an individual response rate of 93 percent.

\section{Variable Measurement}

\section{Dependent Variables}

The dependent variable used in the study is sexual and HIV risk behaviour, which was measured by two separate but related variables, namely the number of current sexual partners and the number of people the respondent had sexual intercourse with during 12 months leading to the survey.

\section{Independent variables:}

This study investigates the effect of two independent variables on men's sexual and HIV risk behaviour.

i) The first independent variable is the percentage of circumcised men between ages 10 and 64 years in the sample population. This variable is derived from self-reported responses to a question that sought to know whether the respondent was circumcised or not.

ii) The second dependent variable is derived from a subsample of uncircumcised men and measures the percentage of uncircumcised men between ages 10 and 64 years, who would be willing to undergo safe male circumcision if it is offered.

Age, education, marital status, religion, place of residence and HIV testing were included as control variables, because conceptually, and as evidenced in a number of studies (see Morris \& Kretzschmar, 1997; Rosenberg et al., 1999; Mah \& Halperin, 20I0), these variables are likely to have an association with the dependent variables, namely, men's sexual and HIV risk behaviours. So, in order to hold constant their likely association with the dependent variable, these variables were included in the net effects regression model, so that the association between the independent variables becomes isolated and discernible.

\section{Statistical analysis}

Bivariate and binary logistic regression is used. Logistic regression results are presented in the form of adjusted odds ratios and percentages, together with 
their $95 \%$ confidence intervals. SPSS version 21 was used for analysis.

\section{Results of the study}

\section{Sample description}

Table I presents the sample socio-demographic characteristics. The sample is predominantly young, with seven out of every ten respondents $(70.3 \%)$ below 35 years of age. Just over a third $(35.4 \%)$ of men in the sample had primary education or below; close to half $(48 \%)$ had secondary education while just under a fifth $(16.7 \%)$ had tertiary education.

Slightly over a quarter $(26.8 \%)$ resided in cities and towns; just under a third $(31.0 \%)$ resided in urban villages while more than two-fifths $(42.2 \%)$ resided in rural areas. Close to two thirds (63.8\%) were never married; a fifth (19.5\%) was cohabiting while $16.6 \%$ were either currently married or had their marital union terminated through widowhood; divorce or separation. Six out of every ten respondents (61.2\%) were Christian, one third (32.5\%) did not identify with any religion while 6.3 per cent belonged to other non-Christian religions.

Just over half (5I.2\%) of men had tested for HIV at least once, and $6 \mathrm{I}$ per cent of those who ever tested did so during the 12 months leading to the survey. Over a fifth (21.0\%) of men had had sex with two or more people during the 12 months leading to the survey; while just under a fifth (16.1\%) had two or more current sexual partners.

Table I: Sample Socio-Demographic \& Behavioural Characteristics

\begin{tabular}{|c|c|c|}
\hline Variable & Number & Percent \\
\hline \multicolumn{3}{|l|}{ Age } \\
\hline $10-14$ & 76992 & 16.5 \\
\hline $15-19$ & 68127 & 14.6 \\
\hline $20-24$ & 63500 & 13.6 \\
\hline $25-29$ & 66064 & 14.2 \\
\hline $30-34$ & 54557 & 11.7 \\
\hline $35-39$ & 36924 & 7.9 \\
\hline $40-44$ & 32382 & 6.9 \\
\hline $45-49$ & 25345 & 5.4 \\
\hline $50-54$ & 18459 & 4.0 \\
\hline $55-59$ & 14694 & 3.2 \\
\hline $60-64$ & 9248 & 2.0 \\
\hline \multicolumn{3}{|l|}{ Education } \\
\hline Primary or less & 145796 & 35.4 \\
\hline Secondary & 197322 & 47.9 \\
\hline Tertiary or higher & 68953 & 16.7 \\
\hline \multicolumn{3}{|l|}{ Residence } \\
\hline Urban & 124958 & 26.8 \\
\hline Urban Villages & 144390 & 31.0 \\
\hline Rural Areas & 196944 & 42.2 \\
\hline \multicolumn{3}{|l|}{ Marital Status } \\
\hline Never married & 296438 & 63.8 \\
\hline Ever married & 77236 & 16.6 \\
\hline Living Together & 90719 & 19.5 \\
\hline \multicolumn{3}{|l|}{ Religion } \\
\hline Christian & $28384 \mid$ & 61.2 \\
\hline Other Non-Christian & 29143 & 6.3 \\
\hline No Religion & 150802 & 32.5 \\
\hline \multicolumn{3}{|l|}{ Ever tested for HIV } \\
\hline Yes & 224837 & 51.2 \\
\hline No & 214390 & 48.8 \\
\hline
\end{tabular}


Tested for HIV in past twelve months

$\begin{array}{lll}\text { Yes } & 137264 & 61.1 \\ \text { No } & 87351 & 38.9\end{array}$

How many people had sexual intercourse with in the past 12 months?
None or One
215964
79.0
Multiple partners
57402
21.0

How many sexual partners do you currently have?

None or One 263854

83.9

Multiple partners

50600

16.1

Table 2: Male Circumcision, and willingness to under Safe Male Circumcision and Sexual Risk Behaviours

\begin{tabular}{|c|c|c|}
\hline Variable & Number & Perc \\
\hline \multicolumn{3}{|l|}{ Ever been circumcised } \\
\hline Yes & 52808 & 11.8 \\
\hline No & 393734 & 88.2 \\
\hline \multicolumn{3}{|l|}{ When were you circumcised? } \\
\hline At birth & 21298 & 42.2 \\
\hline Later in life & 29193 & 57.8 \\
\hline \multicolumn{3}{|l|}{ Where were you circumcised? } \\
\hline Health facility & 35828 & 75.1 \\
\hline Traditional & 11896 & 24.9 \\
\hline \multicolumn{3}{|c|}{ Did you experience any complications? } \\
\hline Yes & 4443 & 9.9 \\
\hline No & 40266 & 90.1 \\
\hline \multicolumn{3}{|c|}{ Would you be willing to be circumcised? } \\
\hline Yes & $266|2|$ & 59.1 \\
\hline No & 184396 & 40.9 \\
\hline \multicolumn{3}{|c|}{ Number of Current Sexual Partners } \\
\hline Zero / One & 660213 & 89.2 \\
\hline Two or more partners & 80145 & 10.8 \\
\hline \multicolumn{3}{|c|}{ Number of People Respondent had sex with during last 12 months } \\
\hline Zero / One & $5|4| \mid 4$ & 85.2 \\
\hline Two or more partners & 89100 & 14.8 \\
\hline
\end{tabular}

Table 2 shows the sample distribution according to men's circumcision status, and the percentage of uncircumcised men who are willing to undergo safe male circumcision, and HIV risk behaviour, as measured by the number of current sexual partners and the number of people the respondent had sexual intercourse with during the 12 months leading to the survey. The results show that just over one in every ten (1I.2\%) men between the ages of 10 and 64 were circumcised, and that close to six out of every ten $(57.8 \%)$ of circumcised men were circumcised later in life (i.e. not at birth), mostly in a modern health facility (75.1\%); and that nine out of ten
(90.1\%) of circumcised men did not experience any complications as a result of the procedure. Among men who were not circumcised, close to six out of every ten $(59.1 \%)$ indicated that they were willing to undergo safe male circumcision, if it was offered.

The results show further that 10.8 per cent of men between the ages of 10 and 64 years had two or more current sexual partners, and that 14.8 per cent of men between ages of 10 and 64 years had had sex with two or more sexual people during the year leading to the survey. 


\section{Male circumcision}

Bi-variate results (Table 3 ) show significant association between male circumcision and men's number of current sexual partners; as well as the number of partners in the 12 months leading to the survey. Male circumcision also shows significant association with other background variables such as age; education, place of residence, marital status, religion; having ever tested for HIV and testing for HIV during the 12 months leading to the survey.

The percentage of circumcised men increases with age, from 5.4 and $7.0 \%$ among men between 10 and 19 years, to 12,16 and 17 per cent among men age groups 20 to $24 ; 25-29$ and 30-34 years, respectively. This proportion is lower among men between 35 and 39 years (1I.0\%) and 40 and 44 years $(10.5 \%)$. The percentage of circumcised men is much lower among men who are over 50 years of age. For example only 6 per cent of men between 50 and 59 years were circumcised, while the corresponding proportion among those aged between 60 and 64 was only $2.5 \%$.

Close to half $(46.4 \%)$ of circumcised men had secondary education; close to a third $(28.7 \%)$ had tertiary education, while a quarter $(24.9 \%)$ had primary education or less. Nearly four out of ten $(37.2$ $\%)$ circumcised men resided in cities and towns, while slightly less than a third resided in urban villages $(31.6 \%)$ or rural areas (31.3\%). Close to half $(47.8 \%)$ of circumcised men were never married; under a third $(29.2 \%)$ were ever married and less than a quarter $(23.2 \%)$ were in cohabiting unions.

Table 3: Percentage of circumcised men and men who are willing to be circumcised by socio-demographic variables and sexual risk behaviours

$\begin{array}{lll}\text { Variable } & \mathrm{N}=446543 & \\ \text { Total } & \begin{array}{l}\% \text { Willing to } \\ \text { be circumcised }\end{array} & \text { Total }\end{array}$

\section{Age}

$10-14$

$15-19$

20-24

$25-29$

$30-34$

$35-39$

40-44

45-49

50-54

55-59

60-64

\section{Education}

Primary or less

Secondary

Tertiary or higher

Residence

Urban

Urban Villages

Rural Areas

Marital Status

Never married

Ever married

Living Together

Religion

Christian

Other Non-Christian
$5.4^{*}$

7.0

12.1

15.9

16.6

11.0

10.5

7.9

5.6

5.5

2.5

24.9*

46.4

28.7

$37.2 *$

31.6

31.3

47.6*

29.2

23.2

57.8*

10.0
69553

64621

61244

64129

53284

36218

31682

25039

17905

13932

8936

137588

223II

67308

120017

139023

187504

28166 I

75321

88892
0.5 *

12.9

14.2

16.1

13.6

8.5

7.8

5.9

4.2

3.1

2.2

31.3*

50.7

18.0

29.0*

31.0

40.0

59.3*

17.2

23.5

271005

28338
$61.7^{*}$

7.0
72738

65613

61300

64222

53468

35854

31243

25177

18078

I 3973

8848

140410

191266

66911

120997

139798

189723 
How many people had sexual intercourse with in the past 12 months?

\begin{tabular}{|c|c|c|c|c|}
\hline None or One & 75.8* & 213362 & $77.3^{*}$ & 212743 \\
\hline Multiple partners & 24.2 & $5704 I$ & 22.7 & 57250 \\
\hline \multicolumn{5}{|c|}{ How many sexual partners do you currently have? } \\
\hline None or One & $83.8^{*}$ & 262400 & $82.4^{*}$ & 260848 \\
\hline Multiple partners & 16.2 & 50416 & 17.6 & 50454 \\
\hline Overall \% & 11.6 & & 59.1 & \\
\hline
\end{tabular}

$$
*<0.05
$$

\section{Association between male circumcision and men's sexual and HIV risk behaviours}

This section presents the results of both the bivariate and logistic regression of the association between male circumcision and men's sexual and HIV risk behaviors.

Male circumcision and number of current partners Table 4 shows logistic regression odds ratios of the association between male circumcision and men's current number of sexual partners. The odds ratios represent the likelihood that a circumcised man will report having two or more current sexual partners. The results show that being circumcised was associated with a $12 \%$ increase in the likelihood of having two or more current sexual partners, compared to uncircumcised men, controlling for other variables in the model.

Other variables that show significant association with number of current sexual partners are age; education, place of residence, marital status, religion; having ever tested for HIV and testing for HIV during the 12 months leading to the survey. For example, men between I0-14 years, $15-19$ and 20 and 24 years were $1.7,2.5$ and 2 times more likely to have two or more current sexual partners compared to those in ages between $35-39$ years. Men who were 25-29 years were 19\% more likely to have two or more current partners compared to those aged between 10 and 14 years. Meanwhile, men between 30-34 years, 40-44 years and 45-49 years are $31 \%, 41 \%$ and $51 \%$ less likely to have two or more current partners compared to those aged 35-39 years.

Having secondary education was associated with $5 \%$ increase in likelihood of having two or more current sexual; partners, while having primary education or less was associated with a $23 \%$ reduction in odds of having two or more partners, compared to men with tertiary education. Compared to men residing in cities and town, those residing in urban villages (Odds $=0.896)$ and rural areas (Odds $=0.808)$ were less likely to have two or more current sexual partners. Being never married (Odds $=0.585)$ and being ever married (Odds $=0.848$ ) was associated with a 40 and $18 \%$ decline in odds of having two or more current sexual partners compared to being in a cohabiting union. 
Table 4: Logistic regression coefficients showing the likelihood that the respondent had multiple concurrent sexual partners

\begin{tabular}{|c|c|c|c|}
\hline \multirow[t]{2}{*}{ Variable } & \multirow[t]{2}{*}{$\operatorname{Exp}(B)$} & \multicolumn{2}{|c|}{$95 \% \mathrm{Cl}$} \\
\hline & & Lower & Upper \\
\hline \multicolumn{4}{|l|}{ Circumcised } \\
\hline Yes & $1.121^{*}$ & $\mathrm{I} .082$ & 1.161 \\
\hline No & 1.000 & & \\
\hline \multicolumn{4}{|l|}{ Age } \\
\hline $35-39$ & 1.000 & & \\
\hline $10-14$ & $1.697 *$ & $\mathrm{I} .545$ & $\mathrm{I} .864$ \\
\hline $15-19$ & $2.589 *$ & 2.458 & 2.727 \\
\hline $20-24$ & $2.009 *$ & 1.912 & 2.112 \\
\hline $25-29$ & $1.187^{*}$ & 1.126 & 1.251 \\
\hline $30-34$ & $0.687^{*}$ & 0.638 & 0.739 \\
\hline $40-44$ & $0.587^{*}$ & 0.535 & 0.644 \\
\hline $45-49$ & $0.489 *$ & 0.432 & 0.554 \\
\hline $50-54$ & 0.095 & 0.897 & 0.955 \\
\hline $55-59$ & 0.604 & 0.576 & 0.633 \\
\hline $60-64$ & 0.377 & 0.294 & 0.484 \\
\hline \multicolumn{4}{|l|}{ Education } \\
\hline Primary or less & $0.768 *$ & 0.735 & 0.803 \\
\hline Secondary & $1.05 I^{*}$ & 1.021 & 1.083 \\
\hline Tertiary or higher & 1.000 & & \\
\hline \multicolumn{4}{|l|}{ Residence } \\
\hline Urban & 1.000 & & \\
\hline Urban villages & $0.896 *$ & 0.869 & 0.923 \\
\hline Rural areas & $0.808 *$ & 0.783 & 0.833 \\
\hline \multicolumn{4}{|l|}{ Marital Status } \\
\hline Never married & $0.585^{*}$ & 0.558 & 0.613 \\
\hline Ever married & $0.848 *$ & 0.823 & 0.873 \\
\hline Living together & 1.000 & & \\
\hline \multicolumn{4}{|l|}{ Religion } \\
\hline Christian & 1.000 & & \\
\hline Other non-Christian & $1.182 *$ & 1.123 & $\mathrm{I} .245$ \\
\hline No religion & 0.998 & 0.971 & 1.026 \\
\hline \multicolumn{4}{|c|}{ Ever tested for HIV/AIDS } \\
\hline Yes & $0.390 *$ & 0.304 & 0.499 \\
\hline No & 1.000 & & \\
\hline \multicolumn{4}{|c|}{ Tested for HIV/AIDS in the past twelve months } \\
\hline Yes & $1.435^{*}$ & $\mathrm{I} .397$ & 1.475 \\
\hline No & 1.000 & & \\
\hline Age group*Circumcision & 0.000 & & \\
\hline
\end{tabular}

$*<0.05$ 
While the odds of having two or more current sexual partners were not significantly different between men who had no religion compared to Christian men, those who belonged to other non-Christian religions were 1.2 times more likely to have two or more current sexual partners compared to Christian men.

The results show further that men who have tested for HIV in the past 12 months were 1.4 times more likely to have two or more current sexual partners compared to men who -did not test for HIV/AIDS in the 12 months leading to the survey. However, having ever tested for HIV/AIDS was associated with a $61 \%$ decline in the odds of having two or more current sexual partners.

Male circumcision and number of people respondent had sex with in the 12 months leading to the survey Table 5 presents logistic regression results of the association between male circumcision and the number of people the respondent had sex with in the 12 months leading to the survey. Circumcised men were I.3 times more likely to report having sex with multiple partners in the 12 past months leading to the survey.

Other variables that show significant association with the number of partners are age; education; place of residence; marital status, religion and HIV testing. For example, men in ages between 15 and 19 years were 2.2 times more likely to have had sex with two or more sexual partners during the 12 months leading to the survey compared to men in ages between 35 and 39 years. Having primary education or less was associated with a $42 \%$ decline in the odds of having had sex with two or more sexual partners during the 12 months leading to the survey, compared to having tertiary education. Residing in urban villages and rural areas were associated with a 12 and $9 \%$ decline in odds of having had sex with two or more sexual partners during the 12 months leading to the survey, compared to men residing in cities and towns.

Table 5: Logistic regression coefficients showing the likelihood that the respondent had sex with multiple partners in the 12 months leading to the survey

\begin{tabular}{|c|c|c|c|}
\hline \multirow[t]{2}{*}{ Variable } & \multirow[t]{2}{*}{$\operatorname{Exp}(B)$} & \multicolumn{2}{|c|}{$95 \% \mathrm{Cl}$} \\
\hline & & Lower & Upper \\
\hline \multicolumn{4}{|l|}{ Circumcised } \\
\hline Yes & $1.288^{*}$ & 1.249 & 1.338 \\
\hline No & 1.000 & & \\
\hline \multicolumn{4}{|l|}{ Age } \\
\hline $35-39$ & 1.000 & & \\
\hline $10-14$ & $1.610 *$ & 1.465 & 1.769 \\
\hline $15-19$ & $2.199 *$ & 2.092 & 2.311 \\
\hline $20-24$ & 1.570 & 1.498 & 1.647 \\
\hline $25-29$ & 0.953 & 0.906 & 1.001 \\
\hline $30-34$ & $0.648 *$ & 0.606 & 0.693 \\
\hline $40-44$ & $0.439 *$ & 0.400 & 0.482 \\
\hline $45-49$ & $0.440 *$ & 0.390 & 0.495 \\
\hline $50-54$ & $0.728 *$ & 0.632 & 0.839 \\
\hline $55-59$ & 0.896 & 0.869 & 0.923 \\
\hline $60-64$ & 0.808 & 0.783 & 0.833 \\
\hline \multicolumn{4}{|l|}{ Education } \\
\hline Primary or less & $0.575^{*}$ & 0551 & 0.600 \\
\hline Secondary & 0.994 & 0.967 & 1.023 \\
\hline Tertiary or higher & 1.000 & & \\
\hline \multicolumn{4}{|l|}{ Residence } \\
\hline Urban & 1.000 & & \\
\hline Urban villages & $0.877^{*}$ & 0.851 & 0.904 \\
\hline Rural areas & $0.906 *$ & 0.879 & 0.933 \\
\hline
\end{tabular}




\section{Marital Status}

$\begin{array}{llll}\text { Never married } & 0.54 I^{*} & 0.518 & 0.566 \\ \text { Ever married } & 0.670 * & 0.650 & 0.690 \\ \text { Living together } & 1.000 & & \end{array}$

\section{Religion}

Christian

Other non-Christian

1.000

No religion

$\begin{array}{lll}1.182 * & 1.123 & 1.244 \\ 0.943 * & 0.918 & 0.969\end{array}$

Ever tested for HIV/AIDS

Yes

$0.469 *$

0.366

0.601

No

1.000

Tested for HIV/AIDS in the past twelve months

Yes

I.224*

1.193

1.256

No

1.000

Age group*Circumcision

0.000

Men belonging to non-Christina religions were I.2 times more likely to have had sex with two or more sexual partners during the 12 months leading to the survey, compared to Christina men, while men with no religion were marginally less likely (Odds 0.943 ) to have had sex with two or more sexual partners during the 12 months leading to the survey. Men who have tested for HIV in past 12 months leading to the survey were 1.2 times more likely to have had sex with two or more sexual partners during the 12 months leading to the survey, compared to men who never tested for HIV, while having ever tested for HIV was associated with a 53 $\%$ decline in likelihood of having had sex with two or more sexual partners during the 12 months leading to the survey.

\section{Willingness to be circumcised}

The results of the bivariate analysis (Table 3 ) also show significant statistical association between uncircumcised men's willingness to undergo safe male circumcision and the number of current sexual partners; as well as the number of people respondents had sex with during the 12 months leading to the survey. Uncircumcised men's willingness to undergo safe male circumcision was also significantly associated with other background variables such as age; education, place of residence, marital status, religion; having ever tested for HIV and testing for HIV during the 12 months leading to the survey

The percentage of men expressing willingness to undergo safe male circumcision increased with age, from 12 to $13 \%$ among men in ages $10-14$ and I519 years respectively. This percentage increases further to 14 and $16 \%$ among men in ages 20 to 24 and 25 to 29 years, respectively, and declines slightly to $14 \%$ among men in the age group $30-34$ years. Beyond 34 years of age, the percentage of men who are willing to undergo safe male circumcision declines steadily with increasing age. For example this percentage declines from $8.5 \%$ among men in ages between 35 and 39 years, to $7.8,5.9$ and $4.2 \%$ among men in age groups 40 to $44 ; 45$ to 49 and 50 to 54 years. Only 3.1 and $2.2 \%$ of uncircumcised men in the ages 55-59 and 60-64 were willing to undergo safe male circumcision.

The percentage of uncircumcised men who were willing to undergo safe male circumcision was highest among respondents with secondary education (50.7\%); followed by respondents with primary education or less $(31.3 \%)$ and was lowest among respondents with tertiary education (18.0\%).

The highest proportion of uncircumcised men who were willing to undergo safe male circumcision was so highest among uncircumcised men residing in rural areas ( $40 \%)$; followed by men residing in urban villages $(31 \%)$ and those residing in cities and town (29\%). This proportion was also highest among never married men (59.3\%), followed by men in cohabiting unions (23.5\%) and those who were ever married (17.2\%). More than six out of ten (6I.7\%) of uncircumcised Christian men were willing to undergo safe male circumcision compared to just under a third $(31.3 \%)$ of uncircumcised men who had no religion, and only $7 \%$ among uncircumcised men who belong to other non-Christian religions

Association between willingness to undergo safe male circumcision and men's sexual and HIV risk behaviours

This section presents the results of both the bivariate and logistic regression of the association be- 
tween willingness to undergo safe male circumcision and men's sexual and HIV risk behaviors.

\section{Willingness and number of current sexual partners}

Table 6 present logistic regression results of the association between uncircumcised men's willingness to undergo safe male circumcision and current number of sexual partners. The results show that uncircumcised men who expressed a willingness to undergo safe male circumcision were 1.9 times more likely to have two or more current sexual partners (Odds $=01.972$ ) .

The results also show that a number of background and behavioral variables such as age, education, place of residence, marital stats, religion and
HIV testing also have significant association with number of sexual partners among uncircumcised men. For example, men between ages 10-14, 1519, 20-24 and between ages 25 and 29 years, were 2,3.8,2.9 and I.6 times more likely to have two or more current sexual partners compared to those between ages 35 and 39 years. The results also show that uncircumcised men willing to be circumcised who had primary education were marginally less likely (Odd $=0.78 \mathrm{I}$ ) to have two or more current sexual partners compared to men with tertiary education or higher, while those with secondary education were marginally more likely (Odds $=1.046)$ compared to men with the same group.

Table 6: Logistic regression coefficients showing the likelihood that the respondent had multiple current sexual partners

\begin{tabular}{|c|c|c|c|}
\hline \multirow[t]{2}{*}{ Variable } & \multirow[t]{2}{*}{$\operatorname{Exp}(B)$} & \multicolumn{2}{|c|}{$95 \% \mathrm{Cl}$} \\
\hline & & Lower & Upper \\
\hline \multicolumn{4}{|c|}{ Willing to be circumcised } \\
\hline Yes & $1.972 *$ & 1.790 & 2.173 \\
\hline No & 1.000 & & \\
\hline \multicolumn{4}{|l|}{ Age } \\
\hline $35-39$ & 1.000 & & \\
\hline $10-14$ & 2.012 & 1.679 & 2.411 \\
\hline $15-19$ & $3.783^{*}$ & 3.431 & 4.171 \\
\hline $20-24$ & $2.858 *$ & 2.596 & 3.145 \\
\hline $25-29$ & $1.668 *$ & 1.505 & 1.848 \\
\hline $30-34$ & $0.374 *$ & 0.312 & 0.448 \\
\hline $40-44$ & $1.55 I^{*}$ & 1.355 & $\mathrm{I} .776$ \\
\hline $45-49$ & $0.162 *$ & 0.137 & 0.192 \\
\hline $50-54$ & 0.998 & 0.971 & 1.026 \\
\hline $55-59$ & 0.585 & 0.558 & 0.613 \\
\hline $60-64$ & 0.489 & 0.432 & 0.554 \\
\hline
\end{tabular}

Education

Primary or less

$\begin{array}{lll}0.781 * & 0.747 & 0.816 \\ 1.046 * & 1.016 & 1.078\end{array}$

Tertiary or higher

1.000

Residence

Urban

1.000

Urban villages

$0.926 *$

0.898

0.955

Rural areas

$0.834^{*}$

0.809

0.861

Marital Status

Never married

$0.604 *$

0.576

0.633

Ever married

$0.834 *$

0.793

0.842

\section{Religion}

Living together

1.000

Christian

1.000

Other non-Christian

I.125* 
No religion

*Ever tested for HIV/AIDS

Yes

No

Tested for HIV/AIDS in the past twelve months

Yes

No

Age of respondent*Willingness
1.000

0.973

1.028

$0.377^{*}$

0.294

0.484

1.000

$1.407^{*}$

1.370

1.446

1.000

0.000
$*<0.05$

Compared to men who were willing to be circumcised and were in cohabiting unions, those who were never married $($ Odds $=0.604)$ and those who were ever married (Odds $=0.834)$ were less likely to have two or more current sexual partners. The results show that men who belonged to non-Christian religions were associated with a $13 \%$ increase in likelihood of having two or more current sexual partners compared to Christian men and that uncircumcised men who were willing to be circumcised who tested for HIV were $72 \%$ (Odds $=0.377$ ) less likely to have two or more current sexual partners. However, the odds of having two or more current sexual partners were not significantly different between men who tested during the 12 months leading to the survey and those who tested earlier than 12 months prior to the survey.

Willingness and number of people respondent had sex with in the 12 months leading to the survey Table 7 shows the association between uncircumcised men's willingness to undergo safe male circumcision and the number of sexual partners they had in the 12 months leading to the survey. The results shows that uncircumcised men's willingness to undergo safe male circumcision was associated with a $30 \%$ increase in the likelihood of having had sex with two or more sexual partners during the year leading to the survey.

Uncircumcised men between the ages of 10-14, 15-19-, 20-24 and 25-29 years were 1.4, 2.8, 1.7 and $\mathrm{I} . \mathrm{I}$ respectively, more likely to have had sex with two or more sexual partners during the year leading to the survey compared to uncircumcised men between aged 35 and 39 years. Being an uncircumcised man older than 24 years of age was associated with a decline in the likelihood of having had sex with two or more sexual partners during the year leading to the survey, compared to uncircumcised men between the ages of 35 and 39 years.

Table 7: Logistic regression coefficients showing the likelihood that the respondent had sex with multiple partners in the 12 months leading to the survey

\begin{tabular}{|c|c|c|c|}
\hline \multirow[t]{2}{*}{ Variable } & \multirow[t]{2}{*}{$\operatorname{Exp}(B)$} & \multicolumn{2}{|c|}{$95 \% \mathrm{Cl}$} \\
\hline & & Lower & Upper \\
\hline \multicolumn{4}{|c|}{ Willing to be circumcised } \\
\hline Yes & I.303* & 1.201 & $1.4 \mid 4$ \\
\hline No & 1.000 & & \\
\hline \multicolumn{4}{|l|}{ Age } \\
\hline $35-39$ & 1.000 & & \\
\hline $10-14$ & $1.44 I^{*}$ & 1.201 & $\mathrm{I} .728$ \\
\hline $15-19$ & $2.838^{*}$ & 2.612 & 3.085 \\
\hline $20-24$ & $1.726 *$ & $1.59 \mid$ & 1.872 \\
\hline $25-29$ & $1.082 *$ & 0.992 & 1.180 \\
\hline $30-34$ & $0.125 *$ & 0.101 & 0.154 \\
\hline $40-44$ & $0.998 *$ & 0.884 & 1.127 \\
\hline $45-49$ & $0.275^{*}$ & 0.216 & 0.349 \\
\hline
\end{tabular}


50-54

$55-59$

60-64

Education

Primary or less

Secondary

Tertiary or higher

Residence

Urban

Urban villages

Rural areas

Marital Status

Never married

Ever married

Living together

Religion

Christian

Other non-Christian

No religion

Ever tested for HIV/AIDS

Yes

No

Tested for HIV/AIDS in the past twelve months

Yes

No

Age of respondent*Willingness
1.000

$\begin{array}{lll}0.897^{*} & 0.87 I & 0.925 \\ 0.893^{*} & 0.866 & 0.920\end{array}$

$0.917^{*}$

0.890

0.944

$0.919 *$

0.892

0.947

1.000

1.000

$\begin{array}{lll}1.125 * & 1.069 & 1.184\end{array}$

$0.94 I^{*}$

0.916

0.967

$0.457 *$

0.356

0.586

1.000

I.210*

1.179

1.242
$*<0.05$

Uncircumcised men with primary education or less were $44 \%$ less likely to have had sex with two or more sexual partners during the year leading to the survey compared to uncircumcised men with tertiary education, while the odds of having had two or more sexual partners were not significantly different between uncircumcised men who had secondary education and those who had tertiary education or more (reference group). Compared to uncircumcised men residing in cities and towns, those residing in urban villages (Odds $=0.897$ ) and rural areas (Odds $=0.893$ ) were associated with a marginal but significant decline in the likelihood of having had sex with two or more sexual partners during the year leading to the survey. Compared to uncircumcised men in cohabiting unions, those who were never married (Odds $=0.917)$ and those who were ever married (Odds $=0.919)$ were associated with a $8 \%$ decline in the likelihood of having had sex with two or more sexual partners during the year leading to the survey.
Uncircumcised men willing to be circumcised who belonged to non-Christian religions (Odds $=1.125$ ) were $13 \%$ more likely to have had sex with two or more sexual partners during the year leading to the survey compared to Christian men, while uncircumcised men with no religion (Odds $=0.94 \mathrm{I}$ ) were marginally less likely to have had sex with two or more sexual partners during the year leading to the survey.

The results show that uncircumcised men who have ever tested for HIV were $54 \%$ (Odds $=0.457$ ) less likely to have had sex with two or more sexual partners during the year leading to the survey, compared to uncircumcised men who never tested for HIV. The results show further that the likelihood of having had sex with two or more sexual partners during the year leading to the survey is significantly different between uncircumcised men who tested during the year leading to the survey, and those who tested earlier than the year leading to the survey (Odds I.2I0). 


\section{Discussion and Conclusions}

While the practice of circumcision is not prevalent in Botswana, the results suggest high levels of willingness and acceptability of safe male circumcision. Results of this study are consistent with other acceptability studies from sub-Saharan Africa (see Caldwell 1994; Bailey et al. 2002; Largarde et al. 2003; Halperin et al. 2005; and Mattson et al. 2005) which show that male circumcision is generally more acceptable and that men are more willing to circumcise than it was believed prior to these studies.

It is also evident that while the percentage of men who are circumcised is low, this proportion not only increased consistently with age, but also that most of the men, especially younger ones, were significantly more likely to have been circumcised in a modern health facility. This probably explains the low rate of complications arising from circumcision cases that were reported in this analysis. The fact that most circumcised men were circumcised in a modern health facility, and that they didn't have any complications augurs well for Botswana's drive to promote safe male circumcision. It would have been a challenge to promote male circumcision if those who underwent the procedure had experienced complications. An earlier study by Keabetswe (2003) documented willingness rates of just under a quarter (23\%) of men over the age of 34 years. The results from this study suggest significantly higher willingness rates generally, including men over the age of 34 years, who were the focus on the study by Keabetswe. This difference is most likely a reflection of increased public education on HIV/AIDS prevention, including safe male circumcision during more recent years.

Findings from this study suggest that education has a significant influence not only on the likelihood of circumcision, but also on willingness to circumcise, however, the impact of education is significant only at secondary and tertiary level. This means that continued efforts to promote and improve access to high education in Botswana is likely to also improve men's propensity towards safe male circumcision in the long run. However, a key finding of this analysis is that the inclusion of a behavioral variable such as HIV testing in the model seems to absorb the previously observed association between secondary education and circumcision. This suggests that men's willingness to undergo safe male circumcision is more a function of men's behavioral attributes, specifically concern to know one's HIV status than their socio-demographic characteristics. Thus, since men's individual HIV risk behavior and HIV risk per- ception are at the center of men's willingness to undergo safe male circumcision than their sociodemographic status, their willingness to undergo safe male circumcision can be enhanced through the current continued efforts to promote safe sexual practices among men.

Sexual behavioral dis-inhibition among circumcised men is a twin concern for efforts aimed at promoting safe male circumcision, as evidenced by the number of studies investigating this possibility among circumcised men (see Mattson et al., 2005; Agot et al., 2007). Evidence of an association between male circumcision and sexual dis-inhibition is at best mixed. For example, while Mattson et al. (2005) found that circumcised men were slightly more likely to be diagnosed with incident STIs than uncircumcised men, the study found no conclusive evidence that circumcision increased HIV risk behavior. In fact, Agot et al., (2007) found that during the first year post-circumcision, circumcised men did not engage in more risky sexual behaviors than uncircumcised men, suggesting that any protective effect of male circumcision on HIV acquisition is unlikely to be offset by an adverse behavioral impact. In contrast, However in South Africa, Lagarde et al. (2003) found a significant association between willingness to be circumcised and the reported number on non- spousal partners. The results of the study have shown that individuals who were circumcised had the propensity to report multiple current sexual partners and relatively more sexual partners during the year leading to the survey compared to those who were not circumcised, thus suggesting the potential for risk compensation among circumcised men.

Meanwhile uncircumcised men who were willing to be circumcised were also more likely to report multiple current sexual partners, or having multiple sexual partners during the year leading to the survey, suggesting that uncircumcised men's willingness to be circumcised is likely to be motivated by the practice of multiple sexual partnerships or having sex with many partners. An even more important finding is that HIV testing leverages men's sexual and HIV risk behavior, but in the opposite direction to what would have been expected, or indeed desired. The finding that among both circumcised and uncircumcised men, having ever tested for HIV in the past 12 months was associated with significant increase in the likelihood of having multiple concurrent partners, and having had sex with more sexual partners during the year leading to the survey suggests that part of the motivation for HIV testing 
might be because those who tested are engaged in sexual and HIV risk practices such as multiple concurrent partnership and the likelihood of having multiple sexual partners.

\section{Conclusion}

This study concludes that circumcised men and men who are willing to be circumcised indulge in sexual risk behavior in Botswana. We recommended that continuous education on the role of circumcision on HIV/AIDS prevention be emphasized so that any misinformation about the role of male circumcision may be corrected forthwith.

\section{Limitations of the study}

The use of secondary data limits the scope of this paper to variables within the dataset. The Botswana AIDS Impact Survey (BAIS III) did not collect enough variables on circumcision to allow in-depth analysis of this topic. Like most demographic surveys, the absence of qualitative data denies this analysis indepth understanding and explanation of patterns observed in the quantitative analysis. The most serious limitation of these data is the fact that questions on willingness to circumcise were asked only of men, specifically uncircumcised men. It would have useful if women were also asked about their willingness to allow their partners to circumcise or even their children. The latter is important because of Botswana's recent adoption of pediatric circumcision of male children as a long-term strategy to reduce their chance of infection. However, despite these limitations, the data provides important insights into the potential of male circumcision as a strategy to mitigate HIV infection, as well as the association between male circumcision, willingness to be circumcised and HIV risk behaviors in Botswana.

\section{Acknowledgement}

We wish to acknowledge Statistics Botswana for allowing the use of the Botswana AIDS Impact Survey III dataset (BAISIII). We also wish to thank the University of Botswana, and the Department of Population Studies, for allowing us the time, facilities and resources to conduct this analysis. Our sincere thanks go to the many reviewers, both colleagues and anonymous reviewers, for their constructive criticism, suggestions and inputs.

\section{Contribution of Authors}

Author I conceived the idea behind this paper, and produced an outline of the manuscript, including analysis plan and methods. Author 2 did the preliminary data exploration and transformation, and produced the initial analysis syntax. Author I produced and interpreted the initial findings. Both author worked on the reviewers' comments and revisions on their respective sections of the paper. Author 2 provided guidance and oversight during the revision of the manuscript; this includes verifying that the data analysis methods, techniques are appropriate, and conclusions accurately reflect the source data. Author 2 ensured that the manuscript was presented and formatted in accordance with stipulated guidelines; and that original data and syntax have been properly archived. Overall, Author I contributed 60 per cent of the work on this manuscript while Author 2 contributed the balance.

\section{References}

Agot KE, Kiarie JN, Nguyen HQ, Odhiambo JO, Onyango TM, Weiss NS.(2007) Male Circumcision in Siaya and Bondo Districts, Kenya: Prospective Cohort Study to Assess Behavioral Disinhibition following Circumcision. Journal of Acquired Immune Deficiency Syndrome. I; 44(I):66-70.accessed online at http://www.ncbi.nlm.nih.gov/pubmed/I 7019365 on 25th April, 2012

Auberch J.D. Wypijewska and K.H. Brodie (eds).1994.Aids and Behaviour: An integrated Approach, Washington DC; National Academy Press.

Auvert, B Et al (2005) Randomized, controlled intervention trial of male circumcision for reduction of HIV in men. Plos Med. UK

Ayiga N., \& Letamo G. (20II) Impact of male circumcision on HIV risk compensation through the impediment of condom use in Botswana, African Health Sciences, Vol I I (4), 550-559.

Bailey R.C., Mugar R.,Poulussen R., \& Abicht H.(2002). The acceptability of male circumcision to reduce HIV infections in Nyanga Province, Kenya. AIDS Care, I4(I)27-40.

Bongaarts J.M, Reinging P. \& Connant F. (1989). The relationship between male circumcision and HIV Seroprevalence. International Journal of Epidemiology, 19,693-697.

Caldwell J.C, \& Caldwell P. (1994). The neglect of an epidemiological explanation for the distribution 
of HIV/AIDS in Sub-Saharan Africa; Exploring Male Circumcision hypothesis.

Cassell MM, Halperin DT, Shelton JD, Stanton D. (2006) Risk compensation: the Achilles' heel of innovations in HIV prevention? British Medical Journal ; 332(754I):605-07

CSO (2009) Botswana AIDS Impact Survey ReportGovernment Printers, Gaborone.

Gray, R. H., Kiwanuka, N., Quinn, T. C., Sewankambo, N. K., Serwadda, D., Mangen, F. W., et al. (2000). Male circumcision and HIV acquisition and transmission: cohort studies in Rakai, Uganda. Rakai Project Team. AIDS, I4(I5), 237I238I. (XIII International Conference)

Gray RH, Li X, Wawer MJ, Gange SJ, Serwadda D, Sewankambo NK, et al. (2003) stochastic simulation of the impact of antiretroviral therapy and HIV vaccines on HIV transmission: Rakai, Uganda. AIDS I7(I3): 194I-5I.

Halperin D.J., Fritz K., McFarland W., \& Woelk G.(2005).Acceptability of adult male circumcision for sexually transmitted diseases and HIV prevention in Zimbabwe. Sexually Transmitted Diseases, 32(4), 238-39.

Halperin, D T. \& Epstein, H., (1997) Why is HIV prevalence so severe in Southern Africa? The role of multiple concurrent partnerships and lack of male circumcision - implications for HIV prevention: Opinion; Southern African Journal of HIV Medicine, Vol25 \# 26; 19-23

Kebaabetswe P., Lockman S., Mogwe S., Mandevu R., Thior I., Essex M., \& Shapiro R.L. (2003). Male Circumcision: An acceptable strategy for HIV prevention in Botswana. Sexually Transmitted Infections, 79(3), 214-219. (PubMed).

Lagarde, E., Dirk, T., Puren, A., Reathe, R. T., \& Bertran, A. (2003). Acceptability of male circumcision as a tool for preventing HIV infection in a highly infected community in South Africa. AIDS, 17(I), 89-95.

Mattson C.I., Bailey R.C, Mugar R., Poulussen R. \& Onyango T.(2005:I).Acceptability of male circumcision and predictors of circumcision preferences among men and women in Nyanza Province, Kenya. AIDS Care, 17(2) I82-94.

Mattson C.L, Campbell R.T, Bailey R.C, Agot K, Ndinya-Achola J.O, Moses S, (2005:2) Risk Compensation Is Not Associated with Male Circumcision in Kisumu, Kenya: A Multi-Faceted Assessment of Men Enrolled in a Randomized Controlled Trial; Plos One accessed online at http://www.plosone.org/article/info:doi/10.137//j ournal.pone. 0002443 on 25th April, 2012
Mah T.L. \& Halperin D.T., (20I0), Concurrent sexual partnerships and the HIV epidemics in Africa: evidence to move forward; - AIDS and Behavior, Vol 14: II-I6 DOI: 10.1007/s I046 I-008-9433x

Mberu B.U. (2010). Risk perception for HIV/AIDS infection among premarital sexually initiated youth in Nigeria; African Population Studies Vol. 24, 3,191-192.

Ministry of Health (20II) Safe Male CircumcisionAdditional strategy for HIV prevention Government Printers.Gaborone.Botswana

Morris, M. \& Kretzschmar, M., (1997) Concurrent partnerships and the spread of HIV, AIDS, Vol II \# 5: 641-648

Ngalande R.C., Levy J., Kapondo C.P.N., Bailey R.C., (in Press). Acceptability of male circumcision for prevention of HIV infection in Malawi. AIDS and Behavior.

Nnko S., Washija R., Urassa M., \& Boerma J.T. (200I).Dynamics of male circumcision practices in North West Tanzania. Sexually Transmitted Diseases, 28(4), 214-18.

Ntozi JPM. (1997) Using circumcision to prevent HIV infection in sub-Saharan Africa: the view of an African. In: Health Transition Review (Australia) 1997; 7 Supplement: 97-100

Rain-Taljaard, R.C., Lagarde, E., Taljaard, D.J., Campbell, C., MacPhail, C., Williams, B., \& Auvert, B. (2003). Potential for an intervention based on male circumcision in a South African town with high levels of HIV infection. AIDS Care. June; 15 (3):3 I5-27.International Conference.

Rosenberg, M; Gurvey, J.E.; Adler, N. Dunlop \& M. Ellen, J. (1999) Concurrent Sex Partners and Risk for Sexually Transmitted Diseases Among Adolescents; Sexually Transmitted Diseases; Vol 26 \# 4: 208-212.

Rosenstock, I. M., Strecher, V. J., \& Becker,M. H. (1994). The health belief model and HIV risk behavior change, in Preventing AIDS: Theories and methods of behavioral interventions, R. J. DiClemente, ed., pp. 5-24

Scott B.E., Weiss H.A \& Viljoen J.I. (2005). The acceptability of male circumcision as an HIV intervention measure among a rural Zulu population, Kwazulu Natal, South Africa. AIDS Care, 17(3), 304-13.

Serwadda D, Wawer MJ, Musgrave SD, Sewankambo NK, Kaplan JE, Gray RH.(1992) HIV Rakai District, Uganda. AIDS 6(9):983- 9. 
Smith D.J. (2003), Imagining HIV/AIDS: Morality and perceptions of personal risk in Nigeria', Medical Anthropology 22(4):343-372.

Weiss, H.A., Quigley, M.A., Hayes, R.J (2000). Male circumcision and risk of HIV infection in subSaharan Africa: a systematic review and meta- analysis. AIDS.(Journal); I4(I5):236 I-70.

Westercamp N. \& Bailey R.C. (2006). Acceptability of male circumcision for prevention of HIV/AIDS in Sub-Saharan Africa: A Review. AIDS Behavior, I I (3), 34 I-355. 